\title{
Severe preeclampsia and eclampsia: adverse obstetric outcomes and prognostic factors
}

\author{
Suparna Grover ${ }^{1}$, Ajay Chhabra ${ }^{2 *}$
}

\author{
${ }^{1}$ Department of Obstetrics and Gynecology, Government Medical College, Amritsar, Punjab, India \\ ${ }^{2}$ Department of Medicine, Government Medical College, Amritsar, Punjab, India
}

Received: 20 June 2021

Revised: 01 July 2021

Accepted: 02 July 2021

\section{*Correspondence:}

Dr. Ajay Chhabra,

E-mail: drajaychhabra@gmail.com

Copyright: () the author(s), publisher and licensee Medip Academy. This is an open-access article distributed under the terms of the Creative Commons Attribution Non-Commercial License, which permits unrestricted non-commercial use, distribution, and reproduction in any medium, provided the original work is properly cited.

\begin{abstract}
Background: Hypertensive disorders of pregnancy are globally a threat to maternal and fetal outcomes. Despite massive efforts worldwide, these disorders continue to be a major adverse influence on the health goals especially in developing countries. The aim of the study was to measure the impact of hypertensive disorders of pregnancy in its most severe form on maternal and fetal outcomes in our region along with the important prognostic factors. The objective of this study was to investigate the maternal and fetal outcome in cases of severe preeclampsia and to evaluate the risk factors and complications associated with adverse outcomes.

Methods: Indoor records of pregnant females at more than 20 weeks gestation with preeclampsia with severe features (as defined by the ACOG practice bulletin 222) and eclampsia admitted over a period of one year in a unit of obstetrics at Government Medical College, Amritsar were studied and results were statistically analysed.

Results: The incidence of hypertension in pregnancy was $11.85 \%$ while that of severe preeclampsia was $6.14 \% .57 .94 \%$ of these women were primigravida's and $80.16 \%$ of the women with severe preeclampsia/eclampsia were in the age group 20-29 years. Severe preeclampsia and eclampsia contributed to $43.75 \%$ of maternal deaths (OR 8.8, $\mathrm{p}$ value $=0.0001)$ and there was increased incidence of stillbirth $(\mathrm{OR} 10.03$, p value $<0.0001)$ and perinatal mortality $($ OR 12.97, $\mathrm{p}$ value $<0.0001)$. The incidence of preterm birth in cases with severe preeclampsia/eclampsia was $57.14 \%$. Severe anemia as a comorbidity along with respiratory distress and renal impairment were associated with increased probability of maternal death.

Conclusions: In addition to ensuring the implementation of routine management principles of, the policy makers should focus on developing critical obstetric care and NICU infrastructure along with dedicated human resources at obstetric centres to manage these high-risk cases. Improvement in the quality of antenatal care can help in diagnosing such patients before the onset of severe features so as to optimize maternal and neonatal outcomes.
\end{abstract}

Keywords: Severe pre-eclampsia, Eclampsia, Maternal death

\section{INTRODUCTION}

Hypertensive disorders in pregnancy continue to be a major threat to the lives of pregnant women in developing countries. Globally, a lot of stress has been placed, many guidelines are in place and there is plenty of ongoing research about timely prediction, timely intervention and evidence guided management of this spectrum of diseases, so that the maternal and neonatal mortality and morbidity can be minimized.

In spite of huge efforts on the part of government agencies, we continue to witness the worst-case scenarios on regular basis at tertiary care hospitals. Such studies can also be considered a reality check on the quality of $\mathrm{MCH}$ services at all levels in the region and may give some valuable 
inputs in planning the roadmap for Sustainable Developmental Goals 2030 (SDG). ${ }^{1}$

\section{Aims and objectives}

The aim of the study was to estimate the impact of preeclampsia in its most severe forms, on maternal and fetal outcomes. The objective of this study was to evaluate the risk factors, parameters and complications associated with an adverse outcome.

\section{METHODS}

It was a retrospective observational study done in an obstetric unit of Bebe Nanki Mother and Child Care Centre attached to Government Medical College, Amritsar, Punjab over one year from April 2015 to March 2016.

The indoor records of pregnant patients admitted with the diagnosis of hypertension in pregnancy during the study period were studied in details, including history, examination findings, investigation results and the course of hospitalization and the most severe cases were selected as per following inclusion criteria.

\section{Inclusion criteria}

Pregnant women with gestational age beyond 20 weeks with eclampsia or with preeclampsia with any of the following Severe Features (As defined by ACOG practice bulletin 222)- (a) systolic blood pressure $160 \mathrm{mmHg}$ or more, or diastolic blood pressure $110 \mathrm{mmHg}$ or more on two occasions; (b) thrombocytopenia (platelet count less than 1 lac/l); (c) impaired liver function as indicated by elevated levels of liver enzymes to more than twice the normal concentrations, or by severe persistent right upper quadrant or epigastric pain unresponsive to medications; (d) renal insufficiency (serum creatinine concentration $>1.1 \mathrm{mg} / \mathrm{dl}$ or doubling in the absence of other renal disease); (e) pulmonary edema, respiratory dysfunction and/or features of cardiac failure; (f) features of imminent eclampsia like headache or visual disturbances. ${ }^{2}$

\section{Statistical analysis}

The results were statistically analysed with MedCalc ${ }^{\circledR}$ online statistical software with $95 \%$ confidence interval and $\mathrm{p}$ value $<0.05$ as statistically significant.

\section{RESULTS}

During the one-year study period there were 2010 live births in the unit from a total of 2051 deliveries with 1,109 vaginal deliveries and 942 caesarean deliveries.

\section{Demographic data}

There were 243 pregnant women admitted with diagnosis of hypertension in pregnancy of which 126 were found to be cases of severe preeclampsia/eclampsia as per the inclusion criteria. Thus, the incidence of hypertension in pregnancy was $11.85 \%$ while that of severe preeclampsia was $6.14 \%$ (Figure 1 ).

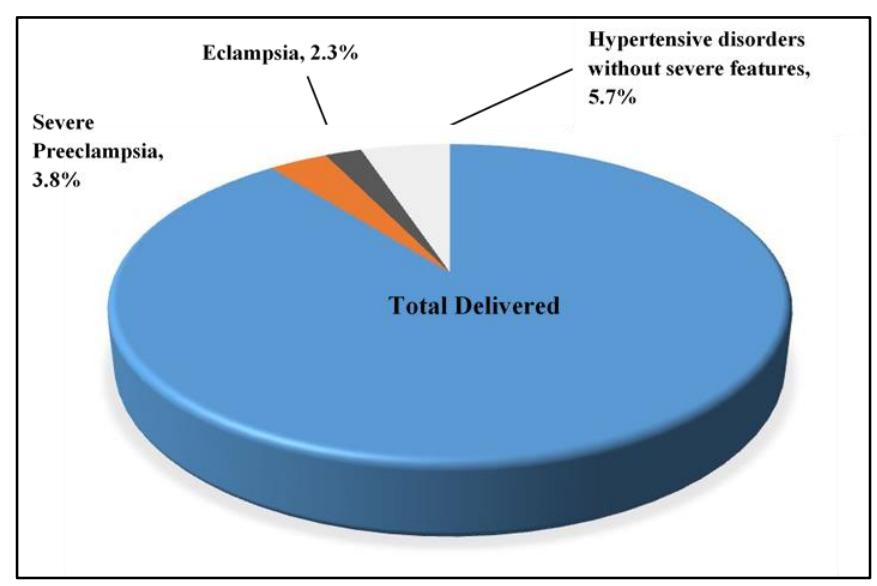

Figure 1: Percentage of severe preeclampsia.

Demographic details of the study group have been described in Table 1. Statistically, none of the age groups were associated with increased probability of maternal death or severe maternal morbidity or adverse fetal outcome.

\section{Blood pressure levels}

44 patients were admitted with diagnosis of eclampsia while another four developed eclampsia later during the course of hospitalization. Systolic blood pressure (SBP) more than $200 \mathrm{mmHg}$ was seen in $9(7.14 \%)$ patients and diastolic BP (DBP) higher than $120 \mathrm{mmHg}$ was observed in $29(23.01 \%)$ patients. 20 patients had spot urine protein equal to or more than $3+(5.87 \%)$. On the other end of the spectrum were 10 of the 48 eclampsia cases that had normal blood pressure and no proteinuria. Maternal deaths were higher in patients with SBP more than $200 \mathrm{mmHg}$ (OR 3.53, p value $=0.28$ ) and that of severe morbidity at SBP more than $180 \mathrm{mmHg}$ (OR 3.8, p value $=0.07$ ) or DBP more than $120 \mathrm{mmHg}$ (OR 3.7, p value $=0.08$ ) but none of these associations were statistically significant.

\section{Gestational age}

Gestational age at the diagnosis of severe preeclampsia/eclampsia was 37 weeks or more in 49 patients $(38.89 \%)$ out of which 10 were diagnosed after 40 completed weeks of gestation. All these 49 term pregnancies were terminated after stabilizing the patients. Of the 77 cases that presented before 37 competed weeks of gestation, six were at less than 28 weeks at presentation, 28 were between 28-34 weeks of gestation and 43 were between 34-37 weeks of gestation. Of the 77 cases presenting at preterm gestation, watchful expectant management was carried out in 10 cases. Other 67 pregnant women were either in labour (21) or had to be terminated by labour induction or caesarean delivery due to complications like eclampsia (32), features of imminent 
eclampsia (11), abruptio placenta (6), fetal distress (10), intrauterine fetal demise (20), HELLP syndrome (1) or multi organ dysfunction (10) due to severe preeclampsia. Out of 10 patients, who were kept under watchful expectant management, three pregnancies complicated by severe preeclampsia at less than 30 weeks gestation were terminated due to intrauterine fetal demise.

Rest of the seven ended in favorable maternal and fetal outcomes. Preterm delivery rate was $57.14 \%$ and the perinatal mortality in this group was $31.75 \%$ with 32 stillbirths and 8 neonatal deaths. While our study group constituted only $6.14 \%$ of all pregnant women delivering in the study period, the 40 perinatal deaths accounted for $35.7 \%$ i.e;. almost one third of all perinatal deaths during this period. Thus, severe preeclampsia and eclampsia had a statistically highly significant association with increased probability of stillbirth (OR 10.03, p value $<0.0001)$ and perinatal mortality (OR 12.97, $\mathrm{p}$ value $<0.0001$ ). The incidence of preterm birth in cases with severe preeclampsia/eclampsia was $57.14 \%$.

\section{Mode of delivery}

Overall caesarean rate in the study population was $45.93 \%$ while it was slightly higher $(53.17 \%)$ in those with severe hypertension which was not a statistically significant difference (OR 1.68, $\mathrm{p}=0.09$ ). The most common indication of caesarean delivery was 23 cases of fetal distress $(18.25 \%)$ followed by 21 cases of failed induction or unfavourable cervix (16.67\%). Abruptio placenta $(6.35 \%)$ and previous caesarean delivery $(5.55 \%)$ were the other more frequent indications of caesarean delivery.

\section{Maternal mortality}

We found around $82.5 \%$ of maternal deaths due to direct obstetric causes and hypertensive disorders were the most common causes, followed by obstetric hemorrhage. In our study period, there were 16 maternal deaths of which seven (7) were due to hypertensive disorders of pregnancy. Thus, hypertensive disorder of pregnancy contributed to $43.75 \%$ of total maternal deaths. 5 of these 7 deaths were a part of our study group and 2 patients who had delivered outside and were brought with complications were not included due to incomplete records of events that happened before their referral. 5 deaths in 126 cases amounted to $3.98 \%$ incidence of maternal death $($ OR $8.8, \mathrm{p}$ value $=0.0001)$ and another $8(6.35 \%)$ patients suffered serious morbidity in the form of organ dysfunction and survived after critical interventions like ventilator support.

\section{Comorbid conditions}

In Table 2, hypertensive disorders were associated with severe anaemia in 16 cases $(12.7 \%)$ and this dangerous comorbidity led to three (3) maternal deaths in this cohort. Severe anaemia with severe preeclampsia/eclampsia was found to have a statistically significant association with the probability of maternal death (OR 13.15, p value $=0.0072$ ). 5 of the hypertensive disorder group had multiple gestation as an aggravating factor and one $(20 \%)$ of them died. This particular maternal death in hypertensive disorder in fact had both multiple gestation and severe anaemia as an aggravating factor. One of the patients in study group had a pre-existing chronic RHD who died and one other had cardiomyopathy as an aggravating factor. The contribution of multiple pregnancy or chronic rheumatic heart disease as an aggravating factor in maternal deaths and severe morbidity due to hypertensive disorders were statistically significant (OR 30.00, p value $=0.02$ ).

\section{Complications of severe preeclampsia}

Important complications observed in this woman with severe preeclampsia/eclampsia included 48 cases $(38.09 \%)$ of eclampsia, nine cases $(7.14 \%)$ of abruptio placenta, $4(3.17 \%)$ of HELLP syndrome, $15(11.9 \%)$ of acute respiratory distress, one $(0.79 \%)$ of coagulopathy, two $(1.59 \%)$ of postpartum haemorrhage, and four (3.17\%) of renal impairment.

The complications associated with higher risk of maternal death (MD) in hypertensive group were respiratory distress (OR 116.8, p value $=0.0016)$, renal impairment (OR 39.67, $\mathrm{p}$ value $<0.0015)$ and HELLP syndrome (OR 9.83, $\mathrm{p}$ value $=0.07$ ) of which only first two were statistically significant. Both these complications are not amenable to magnesium sulphate therapy. Eclampsia (OR 0.39 , $\mathrm{p}$ value $=0.41$ ) and abruptio placenta (no maternal death), on the other hand were not associated with a higher rate of maternal death compared to cases with severe preeclampsia without these complications. The most common interventions required in these cases were 14 $(11.11 \%)$ ICU admissions, 11 needed $(8.73 \%)$ ventilatory support, $25(19.84 \%)$ requiring blood components for anaemia, haemorrhage or coagulopathy (Table 2).

Table 1: Demographic data of the patients with severe preeclampsia and eclampsia.

\begin{tabular}{|llll|}
\hline Demographic data & & Number & Percentage (\%) \\
\hline \multirow{2}{*}{ Booking status of patients } & Booked & 6 & 4.76 \\
\cline { 2 - 4 } & Unbooked & 120 & 95.23 \\
\hline \multirow{3}{*}{ Maternal age (years) } & $<20$ & 6 & 4.76 \\
\cline { 2 - 4 } & $20-29$ & 101 & 80.15 \\
\cline { 2 - 4 } & $30-35$ & 7 & 5.55 \\
\hline
\end{tabular}




\begin{tabular}{|llll|}
\hline Demographic data & & Number & Percentage $(\%)$ \\
\hline \multirow{2}{*}{ Residential background } & $>35$ & 2 & 1.58 \\
\hline \multirow{3}{*}{ Order of pregnancy } & Urban & 23 & 18.25 \\
\cline { 2 - 4 } & Rural & 103 & 81.75 \\
\cline { 2 - 4 } & G1 & 73 & 57.94 \\
\cline { 2 - 4 } & G2-G4 & 18 & 14.28 \\
\hline
\end{tabular}

Table 2: Comorbidities and complications associated with maternal mortality and morbidity.

\begin{tabular}{|c|c|c|c|c|c|c|c|}
\hline \multirow{2}{*}{ Comorbidities } & \multirow{2}{*}{ Total cases } & \multicolumn{3}{|c|}{ Maternal deaths } & \multicolumn{3}{|c|}{ Severe maternal morbidity } \\
\hline & & No. & OR & $P$ value & No. & OR & $P$ value \\
\hline Severe anaemia & 16 & 03 & 13.15 & 0.007 & 01 & 1.23 & 0.85 \\
\hline Multiple pregnancy & 05 & 01 & 1.83 & 0.59 & 00 & - & - \\
\hline Heart disease & 02 & 01 & 30.00 & 0.02 & 01 & 45.4 & 0.02 \\
\hline Chronic hypertension & 03 & 00 & - & - & 01 & 7.9 & 0.11 \\
\hline \multicolumn{8}{|c|}{ Complications of severe preeclampsia } \\
\hline Eclampsia & 48 & 01 & 0.39 & 0.41 & 03 & 0.9 & 0.9 \\
\hline HELLP & 04 & 01 & 9.83 & 0.07 & 03 & 144.45 & 0.001 \\
\hline Renal impairment & 04 & 02 & 39.67 & 0.0015 & 00 & - & - \\
\hline $\begin{array}{l}\text { Respiratory distress, } \\
\text { pulmonary oedema }\end{array}$ & 15 & 05 & 116.8 & 0.0016 & 04 & 17.83 & 0.005 \\
\hline Abruptio placenta & 09 & 00 & - & - & 01 & 1.87 & 0.58 \\
\hline $\mathrm{PPH}$ & 02 & 01 & 30.00 & 0.02 & 00 & - & - \\
\hline
\end{tabular}

\section{DISCUSSION}

Preeclampsia is a pregnancy specific syndrome and accounts for nearly $9 \%$ of all maternal deaths in developing countries of Asia and Africa and is the third leading cause of maternal mortality at global level., ${ }^{2,3}$

American College of obstetrics and gynaecology in 2020 modified the classification of hypertensive disorders of pregnancy to include the concept of preeclampsia with severe features even in the absence of proteinuria. $^{2}$

Bal reported $6.2 \%$ incidence of pregnancy induced hypertension over one year, more than $40 \%$ of which were cases of preeclampsia and eclampsia. ${ }^{4}$ Sailaja reported $2.1 \%$ incidence of hypertensive disorders of which $54.1 \%$ were preeclampsia and eclampsia. ${ }^{5}$ The reported incidence in these studies is much less than the incidence of hypertensive disorders in our study which was $11.85 \%$ for hypertensive disorders and $6.18 \%$ for severe preeclampsia and eclampsia.

Maternal death incidence of $3.97 \%$, perinatal mortality $31.75 \%$ and preterm delivery incidence of $57.14 \%$ in our study group is higher than $1.25 \%, 15.76 \%$ and $35.07 \%$ respectively reported from Indian cases included in multicentric study by Bilano. ${ }^{6}$

Severe preeclampsia and eclampsia led to $43.75 \%$ of MD in our study. Singla et al, in the 10 years audit of MD at a tertiary hospital in Delhi reported $24.4 \%$ of MD due to hypertensive diseases in pregnancy. ${ }^{7}$ While Kaur et al in the 7 years Chandigarh based study found just $8.8 \%$ of MD caused by hypertensive disorders. ${ }^{8}$ A FOGSI study found that hypertensive disorders (eclampsia and severe preeclampsia) remained as the leading cause in the east (34\%) and the north (22\%) zones of India. ${ }^{9}$ This huge variation highlights various regional differences in the challenges to maternal health.

PIERS study group in 2011 proposed the full PIERS (Preeclampsia Integrated Estimate of RiSk) model according to which predictors of adverse maternal outcome included gestational age, chest pain/dyspnoea, oxygen saturation $\left(\mathrm{SpO}_{2}\right)$, platelet count, creatinine, and AST. ${ }^{10}$ Such models may be used to stratify maternal risk during the assessment and surveillance of women admitted with preeclampsia but full PIERS was developed by studying solely, the trends in high income country tertiary obstetric units and may not be generalized to developing countries with their own peculiar challenges and limitations.

Teenage pregnancy, maternal age more than 30 years and first pregnancy are known individual risk factors for preeclampsia. ${ }^{6}$ We found $4.88 \%$ incidence of teenage pregnancy and $7.13 \%$ that of maternal age more than 30 years which are similar to the results of Bej et al who reported $9.8 \%$ preeclampsia cases in teenagers, $75.4 \%$ in 20-29 years and $14.8 \%$ with maternal age 30 years or more. ${ }^{11}$ Sailja et al on the other hand found maximum cases of preeclampsia in $>35$ years age group (46\%) and eclampsia in 26-35 years group $(20.5 \%) .^{5}$

Similarly, our results of $57.94 \%$ preeclampsia cases in nulliparous women is similar to $45.9 \%$ reported by Bej et al and $63.3 \%$ of nulliparous hypertensive cases reported by Bal et al. ${ }^{4,11}$ 
We didn't find either of these age groups or nulliparity to have statistically significant association with increased probability of adverse maternal or fetal outcome. So, although maternal age and parity may help us predict a risk of preeclampsia, they are not significant prognostic markers.

In our study we found severe anaemia to be the comorbidity that is most strongly associated with adverse outcome. Respiratory distress (OR 116.8, p value $=0.0016$ ) and renal impairment $(\mathrm{OR} 39.67, \mathrm{p}$ value $=0.0015)$ were the two complications associated with increased probability of maternal death. Eclampsia cases had a better prognosis and were not associated with increased maternal death or severe maternal morbidity. Hypertensive disorders are a preventable cause of maternal mortality, the main stress has been on regular antenatal clinic visits and timely diagnosis of preeclampsia, timely referral, use of magnesium sulphate for seizure prophylaxis, treatment and timely termination of pregnancy. In our study, 10 of 48 eclampsia cases $(20.83 \%)$ were normotensive and cases without proteinuria. Magnesium sulphate is useful to prevent and treat eclampsia which is the most dreaded complication in hypertensive disorder of pregnancy and all 48 cases of eclampsia and almost half of severe preeclampsia (48.72\%) received magnesium sulphate in our study. Widespread dissemination of information about use of magnesium sulphate for prevention and treatment of seizures in pregnancy may be the reason for the better outcome in eclampsia cases.

A high mortality and morbidity in hypertensive disorders was seen in spite of the use of magnesium sulphate in all eclampsia cases and also in almost half the severe preeclampsia cases.

\section{Limitations}

It was a one-year study with a small study group from a government tertiary center where most of the complicated patients are referred. The results, therefore cannot be generalized to the whole population in terms of the prevalence and complication rates.

\section{CONCLUSION}

Considering these results, we recommend that in addition to ensuring the implementation of routine management principles of clinical and biochemical monitoring, use of antihypertensive drugs, magnesium sulphate and timely termination of pregnancy; the policy makers should focus on developing critical obstetric care and NICU infrastructure along with dedicated human resources at secondary and tertiary centres to manage these high-risk cases.

There is also need to audit the quality of antenatal care as such severe cases should be diagnosed before the onset of severe features to optimise maternal and neonatal outcome.
Without taking some big leaps in controlling maternal deaths due to hypertensive disorders, the SDG may be too distant to achieve.

\section{ACKNOWLEDGMENTS}

Authors would like to thank all the junior residents for their valuable help in data collection.

Funding: No funding sources

Conflict of interest: None declared

Ethical approval: The study was approved by the Institutional Ethics Committee

\section{REFERENCES}

1. United Nations Development Program. Sustainable Developmental Goals 2030, 2020. Available at: https://www.undp.org/sustainabledevelopmentgoals\# good-health. Accessed on 20 June 2021.

2. Gestational Hypertension and Preeclampsia: ACOG Practice Bulletin, Number 222. Obstet Gynecol. 2020;135(6):237-60.

3. Say L, Chou D, Gemmill A, Tunçalp O, Moller AB, Daniels J, et al. Global causes of maternal death: a WHO systematic analysis. Lancet Glob Health. 2014;2(6):323-33.

4. Bal M, Dixit S, Rath SK, Hussain T, Nayak NR, Pati S, Ranjit M. Prevalence and Risk Factors of Pregnancy Induced Hypertension Including Preeclampsia/Eclampsia in Women of Odisha, an Eastern Indian State. Acta Scientif Women's Health. 2021;5(3):17-23.

5. Sailaja B, Cooly V, Salicheemala B, Salaija S. A study on risk factors, maternal and foetal outcome in cases of preeclampsia and eclampsia at a tertiary care hospital of South India. Int J Reprod Contracept Obstet Gynecol. 2018;7:266-71.

6. Bilano VL, Ota E, Ganchimeg T, Mori R, Souza JP. Risk Factors of Preeclampsia/Eclampsia and Its Adverse Outcomes in Low- and Middle-Income Countries: A WHO Secondary Analysis. PLoS one. 2014;9(3):91198.

7. Singla A, Rajaram S, Mehta S and Radhakrishnan G. A Ten Year Audit of Maternal Mortality: Millennium Development Still a Distant Goal. Indian J Community Med. 2017;42(2):102-6.

8. Kaur M, Gupta M, Pandara PV, Rana M, Chakrapani V. Contribution of social factors to maternal deaths in urban India: Use of care pathway and delay models. PLoS One. 2018;13(10):203209.

9. Konar H, Chakraborty AB. Maternal Mortality: A FOGSI Study (Based on Institutional Data). J Obstet Gynaecol India. 2013;63(2):88-95

10. Dadelszen P, Payne B, Li J, Ansermino JM, Broughton PF, Cote AM, et al. Prediction of adverse maternal outcomes in pre-eclampsia: development and validation of the fullPIERS model. Lancet. 2011;377(9761):219-27. 
11. Bej P, Chhabra P, Sharma AK, Guleria K. Determination of Risk Factors for Pre-eclampsia and Eclampsia in a Tertiary Hospital of India: A Case Control Study. J Family Med Prim Care. 2013;2(4):371-5.
Cite this article as: Grover S, Chhabra A. Severe preeclampsia and eclampsia: adverse obstetric outcomes and prognostic factors. Int J Reprod Contracept Obstet Gynecol 2021;10:3005-10. 